aged". They break up and are re-formed, and in doing so exchange material with the pool of small particles suspended in the water column. The incorporation of suspended particles into sinking particles is such that the residence time of suspended particles in the deep sea is only 5-10 years". According to the behaviour expected of particles, all the POC now in the ocean, 30 years after the bomb tests, should have ${ }^{14} \mathrm{C} /{ }^{12} \mathrm{C}$ ratios which are virtually identical to the bomb-contaminated levels observed at the ocean's surface. Druffel and Williams observe that suspended POC below the surface is significantly depleted in ${ }^{14} \mathrm{C}$ with respect to the upper ocean. They argue that the ${ }^{1+} \mathrm{C}$ depletion is probably a dilution effect arising from the bacterial uptake of $l o w-{ }^{1+} \mathrm{C}$ carbon contained in the DOC pool.

Like the carbon in organic particles, the carbon in the DOC pool acquires a bomb ${ }^{1+} \mathrm{C}$ signature when DOC is produced by organisms at the surface. However, the bomb ${ }^{1+} \mathrm{C}$ signal reaches the DOC in the interior of the ocean only as fast as the ocean can advect contaminated water into the interior by its relatively slow overturning motions (with a timescale of decades to centuries). Also, the DOC pool is 50100 times larger than the POC pool and turns over more slowly. Thus, bacteria feeding on DOC incorporate relatively uncontaminated carbon into their cells. As bacteria are eaten and their carbon is incorporated into the tissues of microbial animals, or as bacteria aggregate or otherwise attach themselves onto filterable particles, the low $-{ }^{14} \mathrm{C}$ signature of the DOC dilutes the bomb ${ }^{14} \mathrm{C}$ in the particulate pools. The observations of Druffel and Williams thus appear to confirm that a certain fraction of the particulate carbon in the deep sea has reached the deeper levels of the ocean by the dissolved organic pathway.

Measurements of DOC have been made for over 50 years. But according to Suzuki and Sugimura, the older techniques for oxidizing carbon from the DOC pool extract less than half the total pool ${ }^{6}$. The carbon extracted by the older techniques is also very 'old' with respect to ${ }^{14} \mathrm{C}$

\footnotetext{
1. Druffel, E. R. M. \& Williams, P. W. Nature 347, 172-174 (1990)

2. Honjo, S. J. mar. Res. 36, 469-492 (1978)

3. Silver, M. W. \& Alldredge, A. L. J. mar. Res. 39, 501-530 (1981).

4. Martin, J. H. et al. Deep-Sea Res 34, 267-287 (1987).

5. Suzuki, Y. et al. Mar. Chem. 16, 83-97 (1985).

6. Sugimura, Y. \& Suzuki, Y. Mar. Chem. 24, 105-131 (1988).

7. Toggweiler, J. R. Nature 334, 468 (1988)

7. Toggweiler, J.R. $N$ 8. Toggweiler, J.R. in Productivity of the Ocean: Present and
Past (eds Berger, W. H., Smetacek, V. \& Wefer, G.) 65-83, (J. Wiley \& Sons, Chichester, 1989).

9. Bacon, M. P. \& Anderson, R. F. J. geophys. Res. 87 $2045-2056$ (1982)

10. Williams, P. M. \& Druffel, E. R. M. Nature 330, 246-248 (1987).

11. Degens, E. T. \& Ittekkot, V. in Transport of Carbon and Minerals in Major World Rivers, pt. 2. SCOPEJUNEP Sonderbd 55, (eds Degens, E. T., Kempe, S. \& Soliman, H.) 21-38 (Mitt. Geol.-Paläont. Inst. Univ. Hamburg, 1983).

12. Toggweiler, J. R. Nature 345, 203-204 (1990).
}

NATURE · VOL 347 · 13 SEPTEMBER 1990 (around 6,000 years ${ }^{\mathrm{in}}$ ), and is thus extremely resistant to microbial oxidation. A product of the old-DOC pool size and its ${ }^{1+} \mathrm{C}$ turnover rate suggests that the old DOC is produced at a rate which is only 0.25 per cent of the primary production in the ocean ${ }^{+.10}$. Much of the old DOC may come into the ocean via rivers ${ }^{11}$

The extra DOC extracted by Suzuki and Sugimura is concentrated in the thermocline and upper ocean ${ }^{6}$. To maintain an upper-ocean DOC gradient against the tendency of the circulation to reduce it, the biota of the ocean must produce the new DOC in much greater quantities than the old DOC is produced. If one assumes that there is an upper-ocean new-DOC pool of roughly 60 moles $\mathrm{m}^{-2}$ (a standing crop equivalent to $120 \mu \mathrm{M}$ spread over the upper $500 \mathrm{~m}$; ref. 6) and one assumes that the upper-ocean pool is turned over in $20-50$ years, then the new DOC must be produced at a rate equivalent to $11-28$ per cent of the primary production ${ }^{4}$. Production rates of this magnitude, if valid, attest to a carbon cycle which is dominated by the producers of DOC, whatever they may be ${ }^{12}$, and heterotrophic bacteria. As much as three times more carbon may be transported out of the euphotic zone in the dissolved organic form than is transported by sinking particles.

The new DOC must have a ${ }^{14} \mathrm{C}$ age which is similar to that of the inorganic $\mathrm{CO}_{2}$ in sea water and must be contaminated with bomb ${ }^{14} \mathrm{C}$, although probably not to the same extent as organic particles. No one has yet succeeded in directly measuring the ${ }^{1+} \mathrm{C}$ content of the Suzuki and Sugimura's new DOC. A very powerful statement in support of the dissolved organic pathway in the ocean's carbon cycle awaits proof that the additional DOC extracted by Suzuki and Sugimura contains a much higher ${ }^{1+} \mathrm{C} /{ }^{12} \mathrm{C}$ ratio than the DOC extracted by the old methods.

J. R. Toggweiler is in the Geophysical Fluid Dynamics Laboratory, Princeton University, PO Box 308, Princeton, New Jersey 08542, USA.

\title{
Superconducting boost for goldfish
}

LEVITATING magnets are a familiar sight in superconductivity research. The cause, the Meissner effect - expulsion of magnetic flux lines from a superconducting material - has long been one of the most dramatic manifestations of the superconducting state. But usually the magnets are rather modest - roughly coin-sized - which explains the interest generated by the picture above when it was presented at a recent meeting* by M. Murakami and colleagues from ISTEC in Tokyo. The 2-kg goldfish bowl is resting on a rare-earth magnet levitated over a liquid-nitrogen-cooled $\mathrm{Y}_{1 \cdot 8} \mathrm{Ba}_{2 \cdot 4} \mathrm{Cu}_{3 \cdot 4} \mathrm{O}_{x}$ (YBCO) superconductor.

The levitation in this example is generated by rather more subtle means than the simple Meissner effect. YBCO belongs to

* Workshop on high-temperature superconductivity, University of Cambridge, 13-15 August 1990. the type II class of superconductors, which permit a degree of penetration by magnetic flux. The flux lines tend to get 'pinned' at defects in the material's lattice. The force holding the bowl up is generated by the resistance to rearrangement of the pinned flux lines, which would result as vertical displacement of the magnet changed the flux density. Its strength is proportional to the sample's critical current and grain size. The advance made by Murakami and colleagues is to prevent cracking of the superconductor's grains by incorporating silver particles in the superconducting matrix: these can absorb mechanical strain without affecting the material's superconducting properties. One hope is that the levitation force may be used to create frictionless bearings, in gyroscopes for example.
P.B. 